\title{
A Technical Approach for Promotion of Yakshagana - A Literature Survey
}

\author{
Anantha Murthy ${ }^{1,2^{*}}$ \& Nethravathi P. S. ${ }^{3}$ \\ ${ }^{1}$ Research Scholar, College of Computer Science and Information Science, Srinivas \\ University, Mangaluru, India \\ ${ }^{2}$ Assistant Professor, Dept of M.C.A, NMAMIT, Nitte, Karkala, India \\ OrcidID: 0000-0002-9009-7541; E-mail: anantham2004@ gmail.com \\ ${ }^{3}$ Professor, College of Computer Science and Information Science, Srinivas University, \\ Mangaluru, India \\ OrcidID: 0000-0001-5447-8673; E-mail: nethrakumar590@ gmail.com
}

Area of the Paper: Art Management

Type of the Paper: Research Case Study

Type of Review: Peer Reviewed as per $|\mathrm{C}| \mathrm{O}|\mathrm{P}| \mathrm{E} \mid$ guidance.

Indexed In: OpenAIRE.

DOI: https://doi.org/10.5281/zenodo. 5731287

Google Scholar Citation: IJCSBE

\section{How to Cite this Paper:}

Anantha Murthy, \& Nethravathi, P. S., (2021). A Technical Approach for Promotion of Yakshagana - A Literature Survey. International Journal of Case Studies in Business, IT, and Education (IJCSBE), 5(2), 239-267. DOI: https://doi.org/10.5281/zenodo.5731287

International Journal of Case Studies in Business, IT and Education (IJCSBE)

A Refereed International Journal of Srinivas University, India.

Crossref DOI : https://doi.org/10.47992/IJCSBE.2581.6942.0132

(C) With Authors.

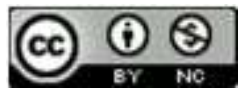

This work is licensed under a Creative Commons Attribution Non-Commercial 4.0 International License subject to proper citation to the publication source of the work.

Disclaimer: The scholarly papers as reviewed and published by the Srinivas Publications (S.P.), India are the views and opinions of their respective authors and are not the views or opinions of the S.P. The S.P. disclaims of any harm or loss caused due to the published content to any party. 


\title{
A Technical Approach for Promotion of Yakshagana - A Literature Survey
}

\author{
Anantha Murthy ${ }^{1,2^{*}} \&$ Nethravathi P. S. ${ }^{3}$ \\ ${ }^{1}$ Research Scholar, College of Computer Science and Information Science, Srinivas \\ University, Mangaluru, India \\ ${ }^{2}$ Assistant Professor, Dept of M.C.A, NMAMIT, Nitte, Karkala, India \\ OrcidID: 0000-0002-9009-7541; E-mail: anantham2004@gmail.com \\ ${ }^{3}$ Professor, College of Computer Science and Information Science, Srinivas University, \\ Mangaluru, India \\ OrcidID: 0000-0001-5447-8673; E-mail: nethrakumar590@gmail.com
}

\begin{abstract}
Background/Purpose: Yakshagana is a theatre style that combines varieties of make-up styles and dressing styles depending on the type of character or role that is to be played on the stage. This article briefly discusses certain areas of Yakshagana where technology can be used for object detection and make-up recognition to classify and identify the characters.

Objective: The main objective of this literature survey is to summarize the techniques used to identify different objects in a Yakahagana image \& to identify the different makeup styles to recognize the type of characters. This paper also recommends the technical methods that can be used to promote Yakshagana.

Methodology: Information is collected from various scholarly articles, books, and web pages. Findings/Results: Based on the analysis of the papers reviewed, it is observed that, no much work is carried out in the field of object detection \& make-up detection in Yakshagana. This survey paper recommends techniques and the methodology that can be applied to the Yakshanaga field to identify and classify the objects and detect the patterns in makeup in Yakshagana roles.
\end{abstract}

Limitations: The study is limited to crown \& jewelry detection and pattern recognition in facial makeup in Yakshagana

Originality: This paper focuses on the summary of techniques used to identify the objects, facial recognition, and pattern in make-up detection.

Paper Type: A Literature survey paper on techniques and methods used to meet the required objectives.

Keywords: Yakshagana, Folk Media, Folk Theatre, Ornament detection, Jewel detection, Object detection, Make-up detection, Face recognition, Pattern Matching, SWOC Analysis.

\section{INTRODUCTION :}

Yakshagana is an open theatre drama also called Bayalaata in the Kannada language where bayalu means an open place and Aata means play. This style of drama is mostly prevalent in Karnataka's coastal districts in numerous variations. The version of Yakshagana is known as Thenku-thittu in Dakshina Kannada district of Karnataka state and Kasaragod district of Kerala state. It is known as Badaga Thittu in Udupi and Uttara Kannada districts. But both of these versions are equally popular in both regions [1].

Yakshagana performance includes background music performed by musicians called Himmela and a dance and dialogue troupe called the Mummela. Both mummela and himmela artists work together on the stage to depict lyrical epics. Little research was done on himmela but till now minimal research was conducted on Mummela [1]. The Mummela artist who is going to perform on the stage has to come up with makeup and proper costume. This survey paper concentrates on recommending different jewelry and ornament detection techniques and makeup style methods that can be used to popularize Yakshagana in the future and to make the beginners learn Yakshagana makeup and dressing styles easily. 
There are different parameters required to identify a character that is played on the Yakshagana stage. The parameters may include object detection techniques to identify crowns, jewels \& swords, pattern recognition modeling to identify the patterns on the facial makeup, and dressing styles. There are different object detection techniques, using which, one can detect objects in an image or a video. In this survey, we have highlighted some of these techniques which can be used for the said purpose.

The topics covered in the paper are as follows: (i) Objectives and methodology of the literature survey, (ii) Summary of related work, (iii) Present status of Yakshagana Industry, (iv) Research gaps and Proposal, (v) Research agenda, (vi) Limitations of Research proposal, (vii) SWOC analysis of research proposal, and (viii) Conclusion.

\section{OBJECTIVES :}

The objectives are the essential components that play a very important role in providing a detailed view of the goal of any research. The following are the objectives of this literature survey :

(1) To determine how the Yakshagana industry has grown and to come up with the research findings that have been already carried out in this industry.

(2) To study the methodology adopted to popularize Yakshagana in the media.

(3) To know the present status of the Yakshagana industry in encouraging people to learn Yakshagana.

(4) To determine the research gaps and to propose the ideal solution to those research gaps.

(5) To list out the research agendas and limitations of the research.

\section{METHODOLOGY :}

The data and the information are retrieved from secondary sources such as books, articles, websites, magazines, and journals. Initially, the data related to Yakshagana are collected from books and articles, then a review process is carried out and identified some of the issues in papers reviewed.

\section{LITERATURE REVIEW :}

Karanth, K. S. (1958) in his paper discussed the history of Yakshagana. In this survey, the author highlighted views on Yakshagana manuscripts, costumes, Literacy, himmela, mummela, and troupes. The author also mentioned about roles of Hindu temples in the Yakshagana field [2]. Ashton M. B.(1969) mentioned that Yakshagana is the most colorful and very famous folk-theatre form found in the coastal region of Karnataka. The themes for Yakshagana are taken from the Puranas of Hindu mythology such as Ramayana, Mahabharatha, Bhagavatha, Devi Purana, etc [3]. Upadhyaya, K. S. (1969) discussed the features of Yakshagana. According to the author, there are no predefined dialogues that an artist has to deliver on the stage. The artist has to dance and then improvise and deliver the stanza presented by Bhaagavatha. The author also highlighted points on costumes and makeup and also discussed every character's unique style of makeup and dressing [4]. Ashton, M. B. (1976) explained in detail about Literature and presentation of Yakshagana, Performance background, staging, dance, and music. The author also explained the different stages that a Yakshagana passes through and how artists use their knowledge in depicting a story in the form of play by considering the example of two different troupes where the same scene is considered from the same Prasanga. [5]. In the view of Bapat, G. V. (1998), Yakshagana is presented in two forms: First, with makeup, dressing, or dance, which is called as Bayalaata, and second without makeup, dressing or dance which is called as taalamaddale. The entertainment media such as television, cinema, etc have had had little impact on Yakshagana's popularity because it satisfies people's emotional needs [6]. Kumar, S. (2010) mentioned that Yakshagana is playing a role in social communication development. The author suggests that the artists and the learners should be given proper training in developing and popularizing Yakshagana and highlighted that Taalamaddale was used a little less in development messages whereas Bayalaata was successful in communication development [7]. Binder, K. (2012) discussed textual and performative re-use in Yakshagana. Yakshagana is not only presenting stories of Puranas but in recent years it is reusing the stories from popular films or epics of local oral which ensures the popularity of this art. The author concluded by saying Yakshagana helps in bringing down the anxiety of the audience because of the adoption of the reusability concept [8]. Kumar, S. (2010) is of the view that changes must take place in Yakshagana along with the time and situation without harming the past beliefs. One must adopt new techniques and technologies to attract people towards Yakshagana [9]. Adding points to this, Padmanabha, K. V., \& Kumar, S. (2019) discussed the diversity in themes of Yakshagana. Non- 
mythological modern themes are explored and presented to showcase the role of Yakshagana in different areas like imaginary, historical, drama, etc [10]. According to Padmanabha, K. V et al. (2020), Yakshagana is not only performed to entertain people but is also successful in creating awareness about health issues and solutions. In recent years Yakshagana performance was organized to educate people on different diseases like HIV/AIDS, COVID-19 [11].

From the above survey, it is clear that Yakshagana is not only entertaining people with its unique style of dance, costumes, makeups, singing, etc, but also it is playing a vital role in educating the illiterate and people who are eager to learn the art of Yakshagana in a shorter period. It is observed that the research is carried out in its history and its diversity in reaching people in the present era. Minor exploration has been carried out by considering make-up and dressing styles. Since each character has its style of dressing and make-up, classifying and identifying the character also plays a crucial role in understanding the theme. Bridging this research gap can be facilitated by considering the technological approach to Yakshagana. This process involves in classification and identification of various types of crowns, swords, jewels in dressing-up, and patterns used in facial make-up. Several machine-learning and image processing algorithms can be implemented to perform the comparative analysis of their efficiencies. The following table summarizes the research findings on object detection, Face recognition, and facial make-up.

Table 1: Related papers on Object detection, Face recognition, and Make-up detection.

\begin{tabular}{|c|c|c|c|c|}
\hline S. No & Author(S) & Year & Method Used & Findings/Results \\
\hline 1 & $\begin{array}{l}\text { Chandan, G. et } \\
\text { al. [12] }\end{array}$ & 2018 & $\begin{array}{l}\text { SSD (Single Shot } \\
\text { Detector) }\end{array}$ & $\begin{array}{l}\text { The authors are with the view } \\
\text { that, in real-time scenarios, } \\
\text { SSD can be used to detect } \\
\text { objects trained with better } \\
\text { accuracy. The same model } \\
\text { can be deployed in } \\
\text { surveillance devices. }\end{array}$ \\
\hline 2 & $\begin{array}{l}\text { Galvez, R. L. et } \\
\text { al. [13] }\end{array}$ & 2018 & $\begin{array}{l}\text { SSD and Faster } \\
\text { RCNN }\end{array}$ & $\begin{array}{l}\text { SSD and Faster RCNN are } \\
\text { compared and found that } \\
\text { SSD can be used with } \\
\text { MobileNetV1to achieve fast } \\
\text { detection and low accuracy. } \\
\text { Use Faster-RCNN with } \\
\text { InceptionV2 to achieve high } \\
\text { accuracy but with low speed. }\end{array}$ \\
\hline 3 & $\begin{array}{l}\text { Ren, Y. et al. } \\
{[14]}\end{array}$ & 2018 & Fast/Faster RCNN & $\begin{array}{l}\text { This paper demonstrates the } \\
\text { process of employing } \\
\text { convolutional architectures } \\
\text { in Fast or Faster RCNN. The } \\
\text { experiment was conducted } \\
\text { on the VOC } 2007 \text { dataset and } \\
\text { found that for object } \\
\text { detection, a classifier with a } \\
\text { convolutional layer is more } \\
\text { successful. }\end{array}$ \\
\hline 4 & $\begin{array}{l}\text { Pham, M. et al. } \\
\text { [15] }\end{array}$ & 2018 & Faster RCNN & $\begin{array}{l}\text { This paper deals with the use } \\
\text { of Faster RCNN in detecting } \\
\text { underground buried objects } \\
\text { in GPR images. It is found } \\
\text { that the proposed technique } \\
\text { improves the detection } \\
\text { results compared to } \\
\text { computer vision methods. }\end{array}$ \\
\hline
\end{tabular}




\begin{tabular}{|c|c|c|c|c|}
\hline 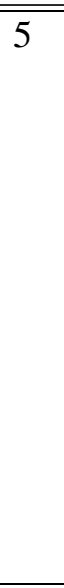 & "Li, Z. et al. [16] & 2018 & "DetNet & $\begin{array}{l}\text { The authors compared one- } \\
\text { stage and two-stage object } \\
\text { detection methods and } \\
\text { noticed the differences } \\
\text { between object detection and } \\
\text { image classification. To } \\
\text { overcome the limitations, the } \\
\text { authors proposed the DetNet } \\
\text { method which has a } \\
\text { backbone network for object } \\
\text { detection. This method is } \\
\text { used for both localization and } \\
\text { classification. }\end{array}$ \\
\hline 6 & $\begin{array}{l}\text { Womg, A. et al. } \\
{[17]}\end{array}$ & 2018 & Tiny-SSD & $\begin{array}{l}\text { The authors are o the view } \\
\text { that the proposed method is } \\
\text { used for real-time embedded } \\
\text { object detection. This model } \\
\text { is smaller than Tiny-YOLO } \\
\text { in size but achieved } 4.2 \% \\
\text { greater mAP compared to } \\
\text { Tiny-YOLO on the VOC } 207 \\
\text { dataset. }\end{array}$ \\
\hline 7 & $\begin{array}{l}\text { Sharma, V. et al. } \\
{[18]}\end{array}$ & 2019 & $\begin{array}{ll}\text { Saliency driven } \\
\text { Faster RCNN model }\end{array}$ & $\begin{array}{l}\text { ASCAL VOC 2007, } \\
\text { PASCAL VOC } 2012 \text { \& } \\
\text { CAMO_UOW dataset is } \\
\text { used for the experiment. } \\
\text { Good detection results were } \\
\text { observed compared to } \\
\text { conventional models. }\end{array}$ \\
\hline 8 & Xu, H. et al. [19] & 2019 & Reasoning-RCNN & $\begin{array}{l}\text { The proposed method was } \\
\text { successful in achieving a } 16 \\
\text { percent upswing on } \\
\text { VisualGenome, } 37 \% \text { on } \\
\text { ADE, and } 15 \text { percent } \\
\text { upswing on COCO. }\end{array}$ \\
\hline 9 & $\begin{array}{l}\text { Benjdira, B. et } \\
\text { al. [20] }\end{array}$ & 2019 & $\begin{array}{l}\text { Faster RCNN and } \\
\text { YOLOV3 }\end{array}$ & $\begin{array}{l}\text { Here the authors compared } \\
\text { Faster RCNN and YOLOV3 } \\
\text { methods on aerial images for } \\
\text { object detection and it is } \\
\text { observed that YOLOV3 } \\
\text { performs better compared to } \\
\text { Faster RCNN in terms of } \\
\text { processing time and } \\
\text { sensitivity. }\end{array}$ \\
\hline 10 & $\begin{array}{l}\text { Mao, Q. C. et al. } \\
{[21]}\end{array}$ & 2019 & Mini-YOLOv3 & $\begin{array}{l}\text { The authors proposed Mini- } \\
\text { YOLOv } 3 \text { from YOLOv } 3 \text { and } \\
\text { they found that their method } \\
\text { achieved better accuracy } \\
\text { compared with YOLOv } 3 \text { in } \\
0.5 \text { detect times on the MS- } \\
\text { COCO dataset. }\end{array}$ \\
\hline 11 & $\begin{array}{l}\text { Choi, J. et al. } \\
{[22]}\end{array}$ & 2019 & Gaussian yolov3 & $\begin{array}{l}\text { Compared to YOLOv3, it is } \\
\text { found that the proposed } \\
\text { algorithm progresses mAP }\end{array}$ \\
\hline
\end{tabular}




\begin{tabular}{|c|c|c|c|c|}
\hline & & & & $\begin{array}{l}\text { by } 3.1 \text { and } 3.5 \text { on BDD and } \\
\text { KITTI data sets. It is } \\
\text { suggested that this method } \\
\text { can be used to achieve higher } \\
\text { accuracy for autonomous } \\
\text { driving applications. }\end{array}$ \\
\hline 12 & Yi, Z. et al. [23] & 2019 & $\begin{array}{l}\text { Tiny- YOLOv3 using } \\
\text { K-means clustering }\end{array}$ & $\begin{array}{l}\text { The authors proposed a } \\
\text { pedestrian detection network } \\
\text { model which resulted in } \\
\text { higher detection accuracy for } \\
\text { VOC2007 pictures but it was } \\
\text { not well successful in } \\
\text { detecting smaller objects } \\
\text { with higher accuracy. }\end{array}$ \\
\hline 13 & Ou, X. et al. [24] & 2019 & $\begin{array}{lr}\text { Moving } & \text { Object } \\
\text { Detection Method via } \\
\text { Resnet-18 } \\
\text { encoding } & \text { using } \\
\text { decoding } & \text { and }\end{array}$ & $\begin{array}{l}\text { Gives better performance } \\
\text { compared to conventional } \\
\text { algorithms but faces some } \\
\text { challenges with smaller } \\
\text { object detection }\end{array}$ \\
\hline 14 & $\begin{array}{l}\text { Haque, M. F. et } \\
\text { al. [25] }\end{array}$ & 2019 & $\begin{array}{l}\text { Resnet Network with } \\
\text { VGG }\end{array}$ & $\begin{array}{l}\text { For accurate object detection } \\
\text { and image classification, the } \\
\text { authors proposed a very deep } \\
\text { convolutional VGG network. } \\
\text { Though it has issues with } \\
\text { localization and training, this } \\
\text { proposal achieved high } \\
\text { accuracy in large-scale } \\
\text { image classification. To } \\
\text { minimize the training error } \\
\text { and to detect a small object, } \\
\text { the Resnet network is } \\
\text { implemented in VGG. }\end{array}$ \\
\hline 15 & Lu, Z. et al. [26] & 2019 & YOLO and Resnet & $\begin{array}{l}\text { This paper proposed a hybrid } \\
\text { network with Resnet and } \\
\text { YOLO combinations for } \\
\text { detecting multiple objects. } \\
\text { Here the natural scene } \\
\text { images are considered for } \\
\text { experiment and it has } \\
\text { resulted in } 75.36 \% \text { accuracy } \\
\text { in detecting multiple objects. }\end{array}$ \\
\hline 16 & Lu, X. et al. [27] & 2019 & Resnet-based SSD & $\begin{array}{l}\text { Resnet-based SSD model is } \\
\text { proposed to increase the } \\
\text { accuracy by } 17.4 \% \text { compared } \\
\text { to VGG but with a high } \\
\text { amount of calculation. }\end{array}$ \\
\hline 17 & Bai, Z. et al. [28] & 2019 & $\begin{array}{l}\text { Combination of } \\
\text { Residual } \\
\text { convolutional neural } \\
\text { network, YOLOv3- } \\
\text { Tiny algorithm }\end{array}$ & $\begin{array}{l}\text { The proposed model is tested } \\
\text { on the PASCAL VOC } \\
\text { dataset. To improve the } \\
\text { result of object detection, a } \\
\text { prediction layer is added to } \\
\text { the neural network. This } \\
\text { model achieved } 64.46 \%\end{array}$ \\
\hline
\end{tabular}




\begin{tabular}{|c|c|c|c|c|}
\hline & & & & $\begin{array}{l}\text { accuracy in real-time target } \\
\text { detection. }\end{array}$ \\
\hline 18 & $\begin{array}{l}\text { Janahiraman, T. } \\
\text { V. et al. [29] }\end{array}$ & 2019 & $\begin{array}{l}\text { SSD MobileNet V2 } \\
\text { and Faster-RCNN }\end{array}$ & $\begin{array}{l}\text { In this paper, SSD MobileNet } \\
\text { V2 and Faster-RCNN } \\
\text { methods are compared to } \\
\text { detect traffic lights. The } \\
\text { experiment is carried out } \\
\text { with } 44 \text { images using the } \\
\text { TensorFlow framework and } \\
\text { the result shows that Faster } \\
\text { RCNNN is better compared } \\
\text { to SSD With an accuracy of } \\
97.01 \% \text {. }\end{array}$ \\
\hline 19 & $\begin{array}{l}\text { Fang, W. et al. } \\
{[30]}\end{array}$ & 2019 & Tinier-YOLO & $\begin{array}{l}\text { The authors proposed a } \\
\text { Tinier YOLO which is four } \\
\text { times smaller than Tiny- } \\
\text { YOLOv3 to achieve } \\
\text { improved } \\
\text { accuracy. }\end{array}$ \\
\hline 20 & $\begin{array}{l}\text { Yundong, L. I. } \\
\text { et al. [31] }\end{array}$ & 2020 & Multiblock SSD & $\begin{array}{l}\text { Multiblock SSD is proposed } \\
\text { to overcome the limitations } \\
\text { of detecting smaller objects. } \\
\text { The experiment is done on } \\
\text { samples of railway scene and } \\
\text { the result showed that the } \\
\text { proposed model achieved an } \\
\text { accuracy o } 96.6 \% \text { which is } \\
\text { greater than } 9.2 \% \text { when } \\
\text { compared with traditional } \\
\text { SSD. }\end{array}$ \\
\hline 21 & $\begin{array}{l}\text { Younis, A. et al. } \\
{[32]}\end{array}$ & 2020 & Mobilenet SSD & $\begin{array}{l}\text { The authors combined } \\
\text { MobileNet and SSD for real- } \\
\text { time object detection in a fast } \\
\text { and efficient manner. This } \\
\text { method is trained and tested } \\
\text { on a minimal number of } \\
\text { images but achieved good } \\
\text { detection accuracy and } \\
\text { increased processing speed. }\end{array}$ \\
\hline 22 & $\begin{array}{l}\text { Mahmoud, A. et } \\
\text { al. [33] }\end{array}$ & 2020 & Mask-RCNN & $\begin{array}{l}\text { FRCN, YOLO1, YOLO2, } \\
\text { SSD, RFCN are compared } \\
\text { with Mask-RCNN with } \\
\text { NWPS dataset and found that } \\
\text { the proposed method } \\
\text { detected objects with 6\% } \\
\text { greater average precision } \\
\text { (AP) than the other } \\
\text { mentioned object detection } \\
\text { methods. }\end{array}$ \\
\hline 23 & He, Z. et al. [34] & 2020 & $\begin{array}{l}\text { Asymmetric tri-way } \\
\text { Faster-RCNN }\end{array}$ & $\begin{array}{l}\text { To avoid the possibility of } \\
\text { the source domain } \\
\text { collapsing, this method was } \\
\text { proposed. }\end{array}$ \\
\hline
\end{tabular}




\begin{tabular}{|c|c|c|c|c|}
\hline$\overline{244}$ & $\begin{array}{l}\text { Zhao, L. et al. } \\
{[35]}\end{array}$ & 2020 & IImproved YOLOv3 & $\begin{array}{l}\text { Here K-means is used to } \\
\text { predict the height and width } \\
\text { of bounding boxes and to } \\
\text { count the distance between } \\
\text { bounding boxes, it uses a } \\
\text { Markov chain. The proposed } \\
\text { method achieved better } \\
\text { performance in terms of F1- } \\
\text { score and mAP compared to } \\
\text { YOLOv3. }\end{array}$ \\
\hline 25 & $\begin{array}{l}\text { Zhao, H. et al. } \\
{[36]}\end{array}$ & 2020 & Mixed YOLOv3-Lite & $\begin{array}{l}\text { To overcome the limitations } \\
\text { like excessive power } \\
\text { consumption and limited } \\
\text { computing power on mobile } \\
\text { smart devices, this model is } \\
\text { proposed. This model is } \\
\text { smaller in size compared to } \\
\text { YOLOv3, tiny-YOLOv3, } \\
\text { and slimYOLOv3 and } \\
\text { achieved better accuracy } \\
\text { with higher efficiency. }\end{array}$ \\
\hline 26 & $\begin{array}{l}\text { Zhang, S. et al. } \\
\text { [37] }\end{array}$ & 2020 & Tiny-YOLO & $\begin{array}{l}\text { The authors proposed a } \\
\text { model to detect object } \\
\text { passengers in the bus. This } \\
\text { paper concentrated on } \\
\text { reducing the calculation } \\
\text { burden and increasing the } \\
\text { operation speed. The result } \\
\text { shows that the proposed } \\
\text { model is four times faster in } \\
\text { detecting passenger objects } \\
\text { compared with traditional } \\
\text { object detection methods. }\end{array}$ \\
\hline 27 & $\begin{array}{l}\text { Long, X. et al. } \\
\text { [38] }\end{array}$ & 2020 & $\begin{array}{l}\text { PP-YOLO based on } \\
\text { YOLOv3 }\end{array}$ & $\begin{array}{l}\text { The authors conducted } \\
\text { experiments on } \\
\text { PaddlePaddle to check the } \\
\text { balance between accuracy } \\
\text { and effectiveness of object } \\
\text { detectors. Based on } \\
\text { YOLOv3, the author } \\
\text { developed PP-YOLO for this } \\
\text { purpose and achieved a } \\
\text { balanced rate of } 45.2 \mathrm{mAP} \\
\text { with } 72.9 \text { FPS efficiency. }\end{array}$ \\
\hline 28 & $\begin{array}{l}\text { Bochkovskiy, } \\
\text { A. et al. [39] }\end{array}$ & 2020 & YOLOv4 & $\begin{array}{l}\text { The authors proposed } \\
\text { YOLOv4 to improve the AP } \\
\text { and FPS of YOLOv3. The } \\
\text { proposed model achieved an } \\
\text { improved AP of } 10 \% \text { and } \\
\text { FPS by } 12 \% \text { in detecting } \\
\text { objects. }\end{array}$ \\
\hline 29 & $\begin{array}{l}\text { Jiang, Z. et al. } \\
{[40]}\end{array}$ & 2020 & $\begin{array}{l}\text { YOLOv4-tiny based } \\
\text { on YOLOv4. }\end{array}$ & $\begin{array}{l}\text { The authors proposed a real- } \\
\text { time fast object detector that } \\
\text { uses the Resnet-D network. }\end{array}$ \\
\hline
\end{tabular}




\begin{tabular}{|c|c|c|c|c|}
\hline & & & & $\begin{array}{l}\text { The proposed model is } \\
\text { suitable for mobile and } \\
\text { embedded devices. }\end{array}$ \\
\hline 30 & $\begin{array}{l}\text { Sun, C. et al. } \\
{[41]}\end{array}$ & 2021 & Mask guided SSD & $\begin{array}{l}\text { The proposed model is } \\
\text { evaluated using Tsinghua- } \\
\text { Tencent } 100 \mathrm{~K} \text { and Caltech } \\
\text { pedestrian datasets and the } \\
\text { results have shown that the } \\
\text { model is successful in } \\
\text { detecting small objects with } \\
\text { comparable performance } \\
\text { with other methods. }\end{array}$ \\
\hline 31 & $\begin{array}{l}\text { Wang, C. Y. } \\
{[42]}\end{array}$ & 2021 & Scaled-YOLOv4 & $\begin{array}{l}\text { The CSP-based YOLOv4 } \\
\text { object identification neural } \\
\text { network scales up and down, } \\
\text { making it suitable for both } \\
\text { small and large networks } \\
\text { while maintaining optimal } \\
\text { speed and accuracy. }\end{array}$ \\
\hline 32 & $\begin{array}{l}\text { Kose, N. et al. } \\
\text { [43] }\end{array}$ & 2015 & $\begin{array}{l}\text { SVM and Alligator } \\
\text { for makeup detection }\end{array}$ & $\begin{array}{l}\text { This paper proposed a facial } \\
\text { make-up detector to reduce } \\
\text { the effect of make-up in face } \\
\text { recognition. Alligator and } \\
\text { SVM classifiers are used for } \\
\text { feature extraction on images } \\
\text { of FCD, YMU, \& MIW } \\
\text { databases and it is observed } \\
\text { that significant accuracy is } \\
\text { achieved in face recognition } \\
\text { with make-up. }\end{array}$ \\
\hline 33 & $\begin{array}{l}\text { Ranjan, R. et al. } \\
{[44]}\end{array}$ & 2017 & $\begin{array}{l}\text { Hyperface based on } \\
\text { Deep CNN, Resnet } \\
\text { for makeup detection }\end{array}$ & $\begin{array}{l}\text { The authors presented an } \\
\text { algorithm to detect the face, } \\
\text { recognize the gender and } \\
\text { pose estimation. The } \\
\text { proposed model was } \\
\text { successful in capturing local } \\
\text { and global data in the face. } \\
\text { The experiment is tested with } \\
\text { AFW, PASCAL, and FDDB } \\
\text { datasets and the result is } \\
\text { effective. }\end{array}$ \\
\hline 34 & $\begin{array}{l}\text { Sun, X. et al. } \\
{[45]}\end{array}$ & 2018 & $\begin{array}{l}\text { Face detection using } \\
\text { Deep learning }\end{array}$ & $\begin{array}{l}\text { An improved version of } \\
\text { RCNN was used to achieve } \\
\text { state-of-the-art performance } \\
\text { by conducting experiments } \\
\text { on n FDDB testbed. }\end{array}$ \\
\hline 35 & $\begin{array}{l}\text { Zhang, C. et al. } \\
{[46]}\end{array}$ & 2018 & $\begin{array}{l}\text { FDNet1.0 - Faster } \\
\text { RCNN for detecting } \\
\text { the face }\end{array}$ & $\begin{array}{l}\text { WIDER FACE data is } \\
\text { considered and found that the } \\
\text { proposed method is more } \\
\text { effective than RCNN. }\end{array}$ \\
\hline 36 & $\begin{array}{l}\text { Masi, I. et al. } \\
\text { [47] }\end{array}$ & 2018 & $\begin{array}{l}\text { Deep Convolutional } \\
\text { Neural Network. }\end{array}$ & $\begin{array}{l}\text { This paper summarizes the } \\
\text { last five years' papers on face } \\
\text { recognition techniques. Here } \\
\text { are the issues related to }\end{array}$ \\
\hline
\end{tabular}




\begin{tabular}{|c|c|c|c|c|}
\hline & & & & $\begin{array}{l}\text { video-based face recognition } \\
\text { and clustering. }\end{array}$ \\
\hline 37 & $\begin{array}{l}\text { Bertacchi, M. } \\
\text { G.et al. [48] }\end{array}$ & 2019 & $\begin{array}{l}\text { CMYK color model } \\
\text { and Neural Networks }\end{array}$ & $\begin{array}{l}\text { The authors compared } \\
\text { CMYK and HSV color } \\
\text { models to detect facial } \\
\text { makeup and the highest } \\
\text { accuracy is achieved on the } \\
\text { face and eye region with the } \\
\text { CMYK model. }\end{array}$ \\
\hline 38 & $\begin{array}{l}\text { Rathgeb, C. et } \\
\text { al. [49] }\end{array}$ & 2019 & $\begin{array}{l}\text { Deep } \\
\text { Networks } \\
\text { conceptual } \\
\text { categorization } \\
\text { beautification }\end{array}$ & $\begin{array}{l}\text { The authors surveyed papers } \\
\text { presented in recent years and } \\
\text { issues and challenges with } \\
\text { face recognition are } \\
\text { discussed. }\end{array}$ \\
\hline 39 & $\begin{array}{l}\text { Ranjan, R. et al. } \\
{[50]}\end{array}$ & 2019 & $\begin{array}{l}\text { Deep Pyramid Single } \\
\text { Shot Face Detector } \\
\text { based on DCNN }\end{array}$ & $\begin{array}{l}\text { The model proposed by the } \\
\text { authors is capable of } \\
\text { detecting tiny faces. The } \\
\text { proposed system is tested } \\
\text { with IJB A, B, C, and IARPA } \\
\text { datasets and achieved near } \\
\text { state-of-the-art results. }\end{array}$ \\
\hline 40 & $\begin{array}{l}\text { Joshi, A. S. et al. } \\
\text { [51] }\end{array}$ & 2020 & Deep learning & $\begin{array}{l}\text { The authors designed a } \\
\text { model which suits speech } \\
\text { tasks. This model detects and } \\
\text { tracks speakers from raw } \\
\text { videos. This model } \\
\text { concentrates on the method } \\
\text { to detect face masks from } \\
\text { video. }\end{array}$ \\
\hline 41 & $\begin{array}{l}\text { Sati, V. et al. } \\
\text { [52] }\end{array}$ & 2020 & $\begin{array}{l}\text { DNN using OpenCV } \\
\text { and Resnet-34 } \\
\text { architecture }\end{array}$ & $\begin{array}{l}\text { The author is of the view that } \\
\text { compared to Haar Cascades, } \\
\text { the Deep Learning Face } \\
\text { Detector of OpenCV gives } \\
\text { better accuracy }(99.96 \%) \text { in } \\
\text { detecting the face. With the } \\
\text { inclusion of facial } \\
\text { embeddings in real-time, it is } \\
\text { possible to achieve an } \\
\text { accuracy of } 79.85 \% \text { in } \\
\text { recognizing the face. In other } \\
\text { scenarios or different } \\
\text { backgrounds, } 86.41 \% \\
\text { accuracy can be achieved. } \\
\text { An accuracy of } 75 \% \text { is } \\
\text { achieved while identifying } \\
\text { facial emotions. }\end{array}$ \\
\hline 42 & $\begin{array}{l}\text { Fang, Z., et al. } \\
\text { [53] }\end{array}$ & 2020 & $\begin{array}{l}\text { Resnet based face } \\
\text { detector }\end{array}$ & $\begin{array}{l}\text { To address the issues related } \\
\text { to accuracy and } \\
\text { computational cost in } \\
\text { identifying a small object, } \\
\text { the authors proposed a } \\
\text { system with structural and } \\
\text { loss function optimization. } \\
\text { The experiment was done }\end{array}$ \\
\hline
\end{tabular}




\begin{tabular}{|c|c|c|c|c|}
\hline & & & & $\begin{array}{l}\text { with FDDB and } \\
\text { WIDERFACE and found } \\
\text { that in the proposed } \\
\text { approach, face detection has } \\
\text { a nice mix of accuracy and } \\
\text { computational cost. }\end{array}$ \\
\hline 43 & $\begin{array}{l}\text { Zhu, Y. et al. } \\
{[54]}\end{array}$ & 2020 & $\begin{array}{l}\text { Tinaface based on } \\
\text { Resnet }\end{array}$ & $\begin{array}{l}\text { The author is of the view that } \\
\text { generic object detection and } \\
\text { face detection are similar and } \\
\text { ASFD-D6, a face detector } \\
\text { method that is extremely } \\
\text { efficient and effective on the } \\
\text { WIDER FACE dataset and } \\
\text { achieved 92.4\% AP } \\
\text { compared to other state-of- } \\
\text { art methods. }\end{array}$ \\
\hline 44 & $\begin{array}{l}\text { Ding, X. et al. } \\
{[55]}\end{array}$ & 2020 & Deep Learning model & $\begin{array}{l}\text { To detect swapped faces, the } \\
\text { authors provided a } \\
\text { comparison to human } \\
\text { subjects by developing a } \\
\text { website, differentiating real } \\
\text { and fake images, and } \\
\text { creating a swapped face } \\
\text { dataset that can be used by } \\
\text { the researchers for further } \\
\text { research. }\end{array}$ \\
\hline 45 & $\begin{array}{l}\text { Mandal, B. et al. } \\
{[56]}\end{array}$ & 2021 & Resnet-50 & $\begin{array}{l}\text { This paper focuses on } \\
\text { identifying the people with } \\
\text { face masks using deep } \\
\text { learning. The authors used } \\
\text { Resnet-50 architecture for } \\
\text { training. When the faces are } \\
\text { occluded, the performance of } \\
\text { convolutional networks is } \\
\text { bad }\end{array}$ \\
\hline 46 & $\begin{array}{l}\text { Al-ghanim, F. J. } \\
\text { et al. [57] }\end{array}$ & 2021 & $\begin{array}{l}\text { HOG and } \begin{array}{r}\text { SVM } \\
\text { Machine learning } \\
\text { detector. }\end{array} \\
\end{array}$ & $\begin{array}{l}\text { This paper proposed a } \\
\text { method to detect faces with } \\
\text { makeup under different } \\
\text { conditions. The experiment } \\
\text { was done with the DMFD } \\
\text { dataset using HOG and SVM } \\
\text { detector. This method } \\
\text { achieved an accuracy of } \\
99.3 \% \text { in detecting the faces } \\
\text { with make-up. }\end{array}$ \\
\hline 47 & $\begin{array}{l}\text { Rathgeb, C. et } \\
\text { al. [58] }\end{array}$ & 2021 & $\begin{array}{l}\text { Deep Face } \\
\text { Representations } \\
\text { M-PAD System }\end{array}$ & $\begin{array}{l}\text { The authors conducted } \\
\text { experiments on the MIFS } \\
\text { database. The proposed } \\
\text { model distinguishes makeup } \\
\text { presentation attacks and } \\
\text { genuine authentication } \\
\text { attempts. }\end{array}$ \\
\hline 48 & $\begin{array}{l}\text { Lobo, V S. et al. } \\
{[59]}\end{array}$ & 2021 & Explorative Study & $\begin{array}{l}\text { Not only in terms of number } \\
\text { and variety, but also in terms }\end{array}$ \\
\hline
\end{tabular}




\begin{tabular}{|c|c|c|c|c|}
\hline & & & & $\begin{array}{l}\text { of an actual audience, the } \\
\text { Indian entertainment } \\
\text { industry has evolved, } \\
\text { expanded, and is unique. The } \\
\text { internet and outdoor } \\
\text { entertainment appear to cater } \\
\text { to two distinct public } \\
\text { demands. Nowadays } \\
\text { Yakshagana is becoming } \\
\text { famous both in online and } \\
\text { offline shows. }\end{array}$ \\
\hline 49 & $\begin{array}{l}\text { Naik, A. D. et al. } \\
{[60]}\end{array}$ & 2021 & $\begin{array}{ll}\text { CNN and } & \text { RNN, } \\
\text { Geometric } & \text { Deep } \\
\text { Learning } & \end{array}$ & $\begin{array}{l}\text { The authors represented 3D } \\
\text { images as point clouds by } \\
\text { applying geometric deep } \\
\text { learning to classify Indian } \\
\text { classical dance forms } \\
\text { including Yakshagana. Since } \\
\text { CNN cannot be applied to } \\
\text { non-Euclidean data, this } \\
\text { model is proposed. }\end{array}$ \\
\hline 50 & $\begin{array}{l}\text { Somayaji, S. et } \\
\text { al. [61] }\end{array}$ & 2021 & Explorative research & $\begin{array}{l}\text { The author is of the view that } \\
\text { many domains associated } \\
\text { with Yakshagana necessitate } \\
\text { technical research to assist } \\
\text { artists and learners. The } \\
\text { author discussed the } \\
\text { necessity of adopting } \\
\text { technology in preparing the } \\
\text { ornament called } \\
\text { Bhujakeerthi. }\end{array}$ \\
\hline
\end{tabular}

Deep learning has gotten a lot of attention over the last decade and has become a dominant AI technology. Object recognition is one of the most interesting aspects of deep learning and computer vision. In their paper, Hu, H., et al (2018) [62] proposed an object relation module to improve object recognition efficiency. It assesses the efficacy of object relationship modeling in CNN-based detection. Some of the papers related to object detection are reviewed on applications like face detection, pedestrian detection, etc. and analysis is done on the challenges and improvements in recent years in the area of object detection [63]. Zhao, Z. Q. et al (2019) [64] have given a review on a comprehensive overview of deep learning-based object identification frameworks that handle a variety of subproblems, including occlusion, clutter, and poor resolution, with varying degrees of R-CNN modification. According to Ghiasi, G., et al (2019) [65], NAS-FPN architecture achieved better latency and accuracy compared to the state of art object detection models. Zhao, J. X., et al (2019) [66] proposed a model to solve the problem of coarse object boundaries. EGNet was designed for salient object detection. With the use of salient edge characteristics, the salient object boundaries and localization are improved. In their paper, Tian, Z., et al (2019) [67] have proposed FCOS to tackle object recognition in a per-pixel prediction approach. This approach is anchor box-free and avoids the complications that occur during training. Zhou, X., et al (2019) [68] proposed a bottom-up approach to detect objects by grouping center and extreme points. This approach resulted in a competitive segmentation result on the MSCOCO data set. Qin, X., et al (2019) [69] proposed a modular novel end-to-end boundary aware model called BASNet for accurate salient object detection. According to Shao, S., et al (2019) [70], For object detection and semantic segmentation, Objects 365 can be a better feature learning dataset. The capacity of Object365 to generalize has also been demonstrated on few tasks. In their paper, Brazil, G., et al (2019) [71] have proposed a technique to improve 3D parameter estimation. The proposed approach was successful in detecting 3D objects on the KITTI dataset. Pang, J., et al (2019 [72] have projected Libra R-CNN to improve the detection performance. It is observed that, on the difficult MS COCO 
dataset, Libra R-CNN provides considerable improvements. For both two-stage and single-stage detectors, Libra R-CNN generalizes effectively to diverse pillars. To allow easy and fast multi-scale feature fusion, the authors Tan, M., et al (2020) [73] proposed a BiFPN pyramid network. EfficientDet, an object detector was developed and achieved more efficient results.

The task of executing real-time object detection with quick inference while retaining a base level of accuracy is known as real-time object detection. Many authors have researched real-time object detection and some of the recent researches is highlighted here. In their paper, Kim, K. H., et al (2016) [74] have presented an approach to achieving state of art accuracy in multi-category object detection tasks by reducing the computational cost using recent technical innovations. This approach can be used for sentiment analysis and face recognition along with object detection. Redmon, J., et al (2016) [75] have used basic YOLO to process images in real-time with 45 frames per second. But compared to state of art approaches, this method creates more localization faults and predicts false positives. In their study Mao, H., et al (2016) [76], offered a pipelined object detection execution on an embedded platform and found that Fast R-CNN is the solution for achieving high energy-efficient real-time performance. Huang, R., et al (2018) [77] have focused more on YOLO-LITE. In a variety of devices, this model has increased the accessibility of real-time object detection. It is found that, for lightweight real-time object detection networks, this model has several contributions.

For camera-based object detection, Ophoff, T., et al (2019) [78] have investigated an approach that increases the performance of single-shot detection networks. In both accuracy and localization of detection, this fusion model outperforms the baseline RGB network. In their paper, Lu, S., et al (2019) [79] proposed a real-time object detection algorithm for videos using the YOLO network. This approach improved the original YOLO algorithm with high detection speed but it is not effective in detecting small objects. Liu, L., et al (2019) [80] have designed a model for AR/MR systems. This model enables high accuracy in object detection and reduces false detection errors. Liu, Z. et al (2020) [81] have proposed Training-Time-Friendly Network (TTFNet) which aids in increasing the learning rate and speeding up the training process. This approach outperformed SSD3 and YOLOv3. In their paper, Jiang, Z., et al (2020) [82] have proposed YOLOv4-tiny. This model is best suited for real-time object detection in embedded systems and mobiles.

A facial recognition system is a piece of software that compares a human face in a digital image or video frame to a database of faces. It locates and measures face features from a given image, and it's widely used to verify individuals through ID verification services. Few recent kinds of research in this area by different authors are described here. In their paper, Masi, I., et al (2018) [83], have summarized advances in face recognition in the last five years in the area of computer vision and discussed SOTA training procedure, face processing part, transfer learning and verification, and identification in face recognition. Wang, F., et al (2018) [84] investigated the relationship between different types of noise, techniques to clean up data, including conducting large user research on the impact of data labeling strategies on annotation accuracy. On recent ten face recognition standards, including a new large-scale image database with trillions of pairs and a large-scale video dataset, Deng, J., et al (2019) [85], gave possibly the most complete investigational assessment against all current state-of-the-art face recognition systems. It is observed that ArcFace consistently outperforms the current state of the art and is simple to build with minimal computational overhead. In their research, Guo, G., et al (2019) [86], have highlighted problems related to face recognition by summarizing about 330 researches in this area. Although the accuracy of face recognition for various still image-based face matching has increased, there are still certain problems in practice. To maintain an equality of opportunity during the race of applying technology in face detection, Deng, J., et al (2019) [87] have defined light and large model tracks and released DeepGlint-Image with $1.8 \mathrm{M}$ images and IQIYI-Video with $0.2 \mathrm{M}$ videos data sets. Adjabi, I., et al (2020) [88] have presented views on the past of face recognition technology, the current trends, and the upcoming instructions. More concentration is given to 2D and 3D face recognition methods and deep learning approaches. In their research, Chang, J., et al (2020) [89] have proposed DULcls and DULrgs methods to maintain data uncertainty learning for face recognition and gave an in-depth investigation of how adding uncertainty estimation reduces the negative effects of noisy data and influences feature learning. In this paper, Wang, M., et al (2021) [90] have summarized and compared the most regularly utilized databases for model training and evaluation and reviewed miscellaneous scenes and technical challenges in deep face recognition. In the rapid advancement of deep FR approaches, a summary of different network designs and loss functions is suggested. In their 
paper, Deng, J., et al (2021) [91] have focused on detecting faces with facial masks. The research also concentrated on detecting non-masked faces. Different top-rated methods are considered and work is still in progress.

Facial makeup has the power to change a person's appearance. The accurateness of automated face recognition systems, as well as methods for evaluating age and beauty from faces, may be harmed as a result of this change. The approach used by Chen, C., et al [92] uses a classifier to assess the presence or absence of makeup by extracting a feature vector that captures the shape, texture, and color features of the input face. In their paper Kotwal, K., et al (2019) [93] proposed a PAD procedure to recognize facial makeups and achieved an accuracy of 93\% in identifying the facial makeups on the AIM dataset. In a face recognition system, Saeed, U., et al (2021) [94] investigated the effectiveness of illumination normalization strategies for reducing the fluctuations produced by cosmetics. Experiments on both confined and unconstrained databases reveal that lighting normalization approaches significantly improve face recognition results. In their research Alzahrani, T., et al (2021) [95] have conducted a comparative study and designed a automated system for identifying facial makeup from an image. Experiment was done with 2479-labelled images and four hundred and forty-six unlabelled images and achieved an accuracy of $88.33 \%$. Gulati, K., et al (2021) [96] have designed a high-quality makeup recommendation system and contributed to the domain of this area. The work was appreciated by the users of this system. According to Ibsen, M., et al (2021) [97], face recognition systems are widely used in almost all areas to identify individuals. Few anomalies exists though many researches have taken place. To tackle with these anomalies, anomaly detection framework is designed and experimented on many databases and the system was successful in detecting the anomalies on images.

\section{PRESENT STATUS :}

At present, neither existing algorithms are used nor new algorithms are developed to identify the dressing styles or makeup styles to recognize the characters played by an artist. One has to go to Chouki (dressing room/green room) to get knowledge about crowns, ornaments, or jewels used. It is also very difficult to understand or identify the makeup styles used for different roles in Yakshagana. Visiting the dressing room and addressing the artist to gain information is the only option in the scenario. Just paying attention to the story or watching Yakshagana is not sufficient to gain thorough knowledge about Yakshagana. The audience should have a complete idea of how the dressing is done, what are the jewels or ornaments used, how the makeup has to do, and so on to understand Yakshagana completely. The audience without an idea about Yakshagana feels very difficult to follow the ongoing sequence. Therefore, to help the Yakshagana fans, we have identified the research gaps and came up with a research proposal with an ideal solution. Currently, there are no algorithms designed or developed and no existing algorithms on either object detection or facial recognition are used to identify crowns, jewels, makeup styles, and characters in Yakshagana.

There are different varieties of crowns available for different types of roles played in Yakshagana. The following table gives the descriptions of different types of crowns used in Yakshagana.

Table 2: Crown types

\begin{tabular}{|l|l|}
\hline Type of Crown & $\begin{array}{l}\text { Nevi Kireeta (Mudi) } \\
\text { This type of crown is used in characters like Devi, Vishnu, Bhoodevi, Laxmi, } \\
\text { etc }\end{array}$ \\
\hline
\end{tabular}




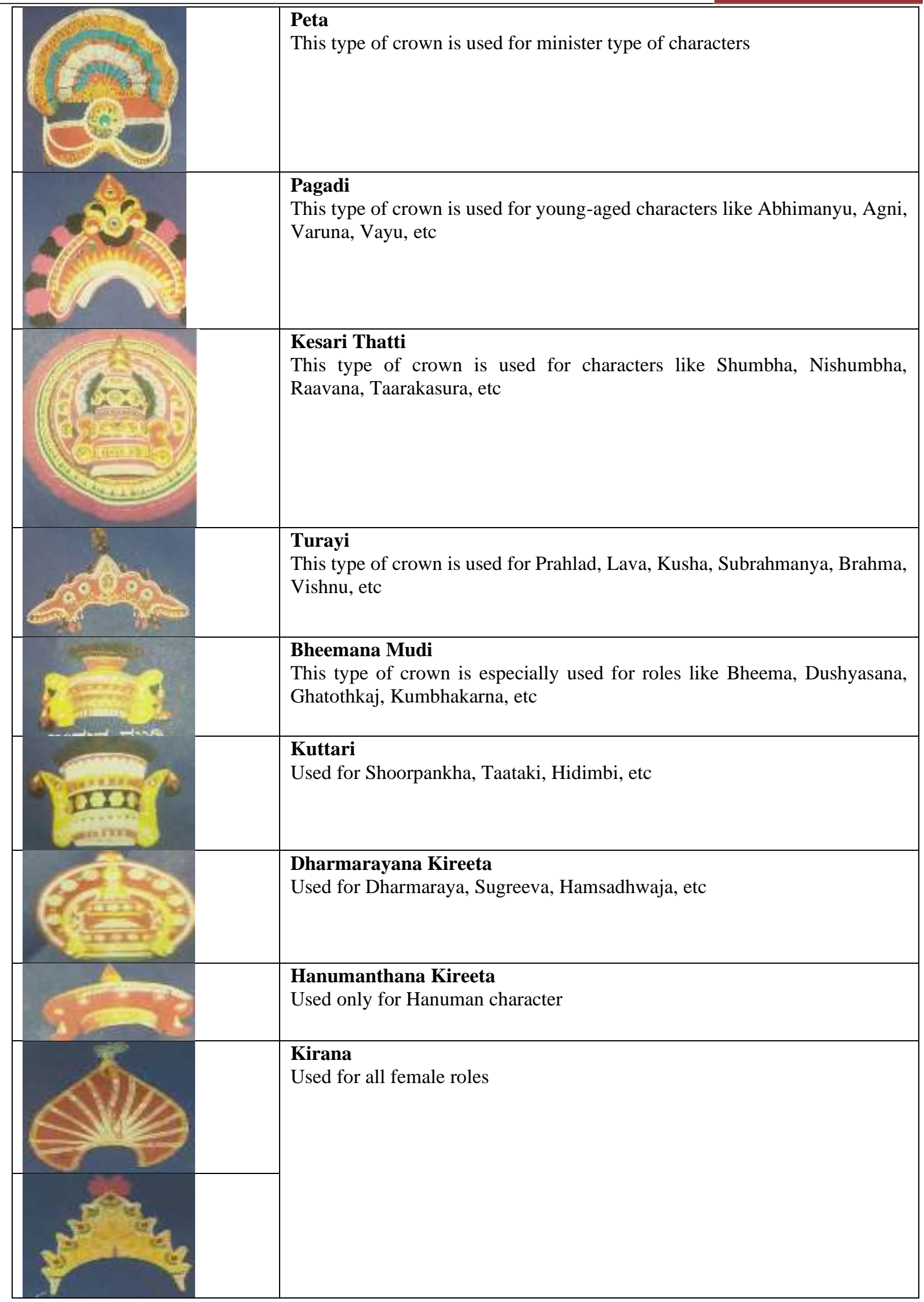




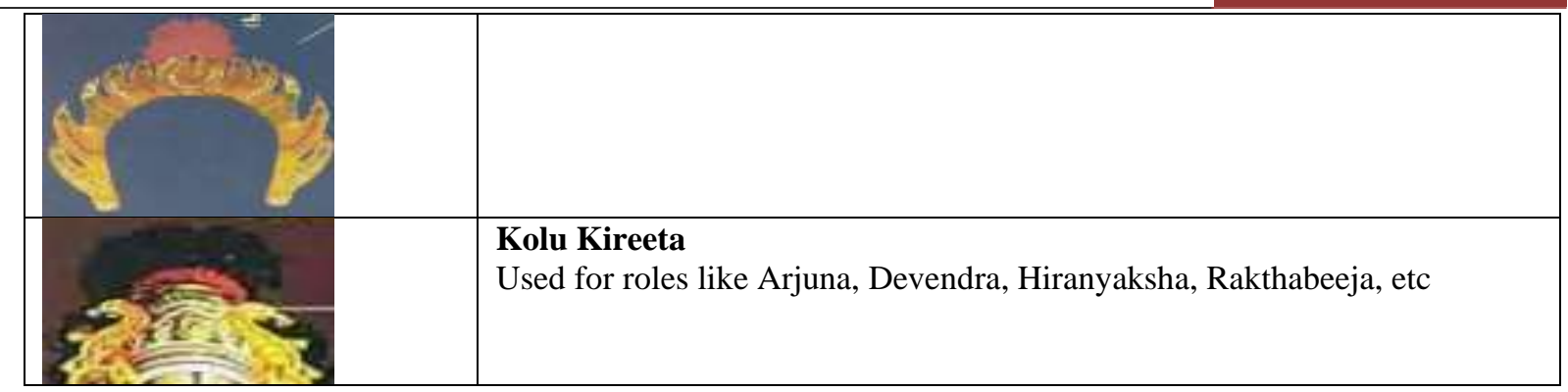

Every type of character in Yakshagana has its unique style of dressing. Dressing looks beautiful with varieties of jewels. The following table lists some types of jewels used during the dressing.

Table 3: Jewel types

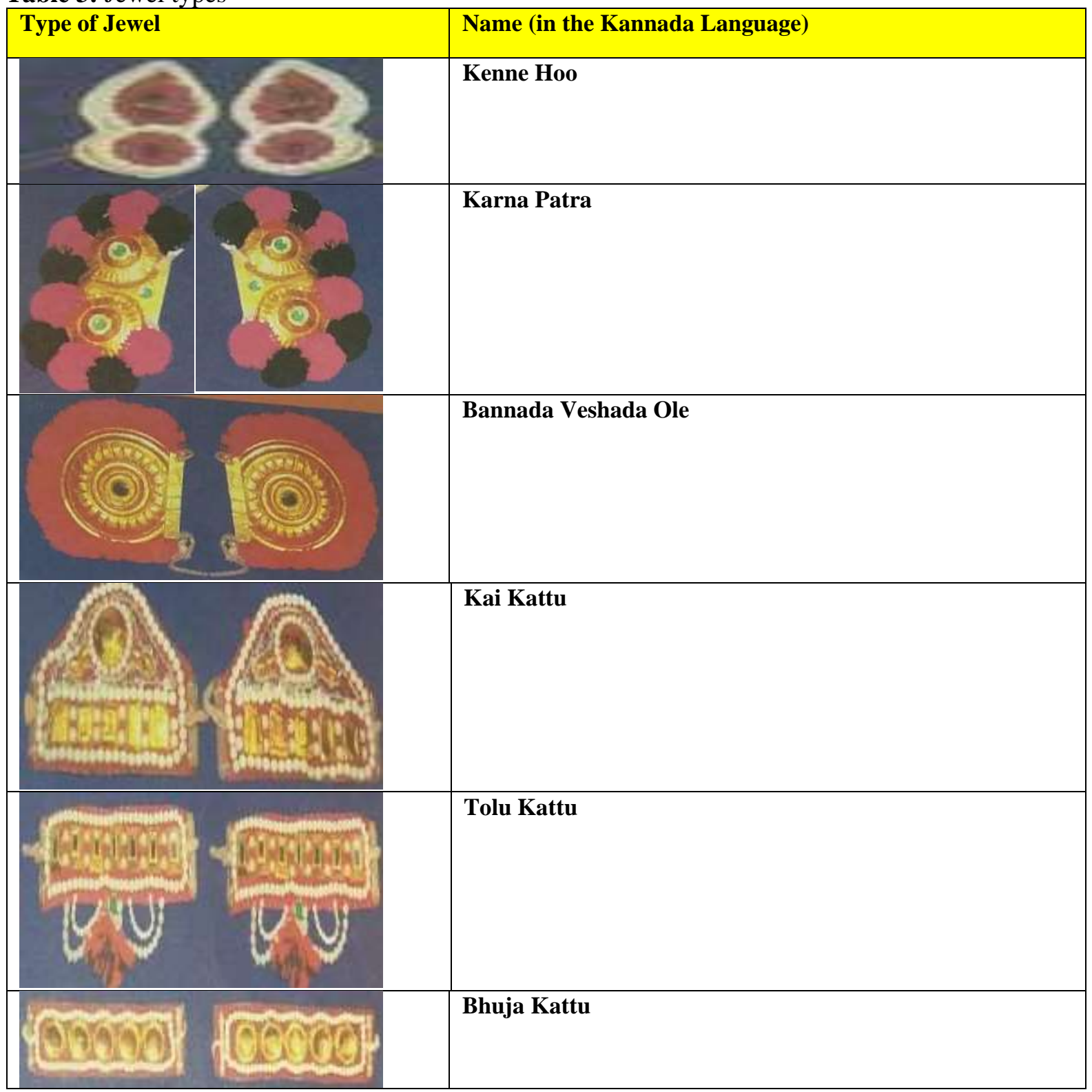




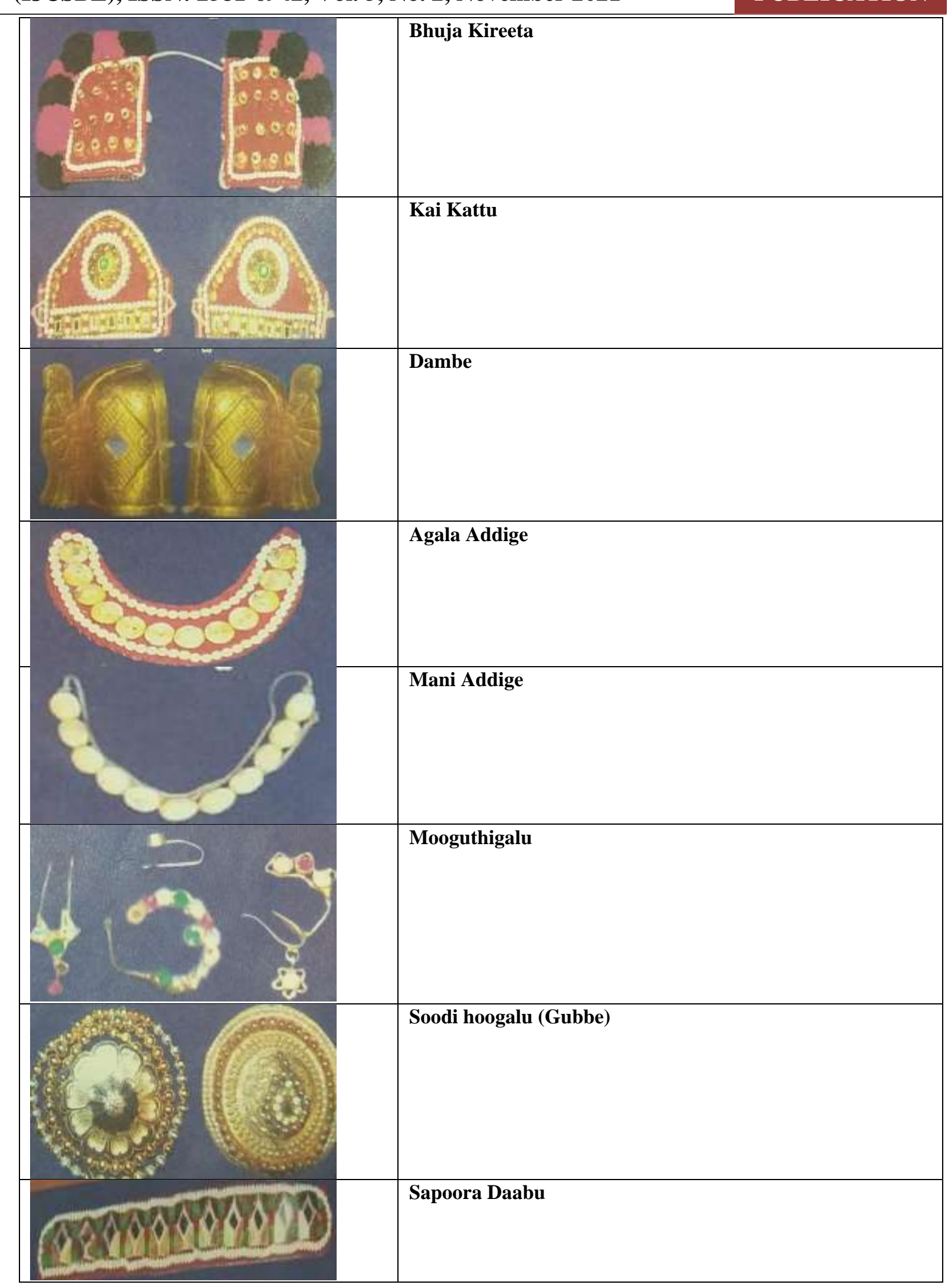


International Journal of Case Studies in Business, IT, and Education (IJCSBE), ISSN: 2581-6942, Vol. 5, No. 2, November 2021

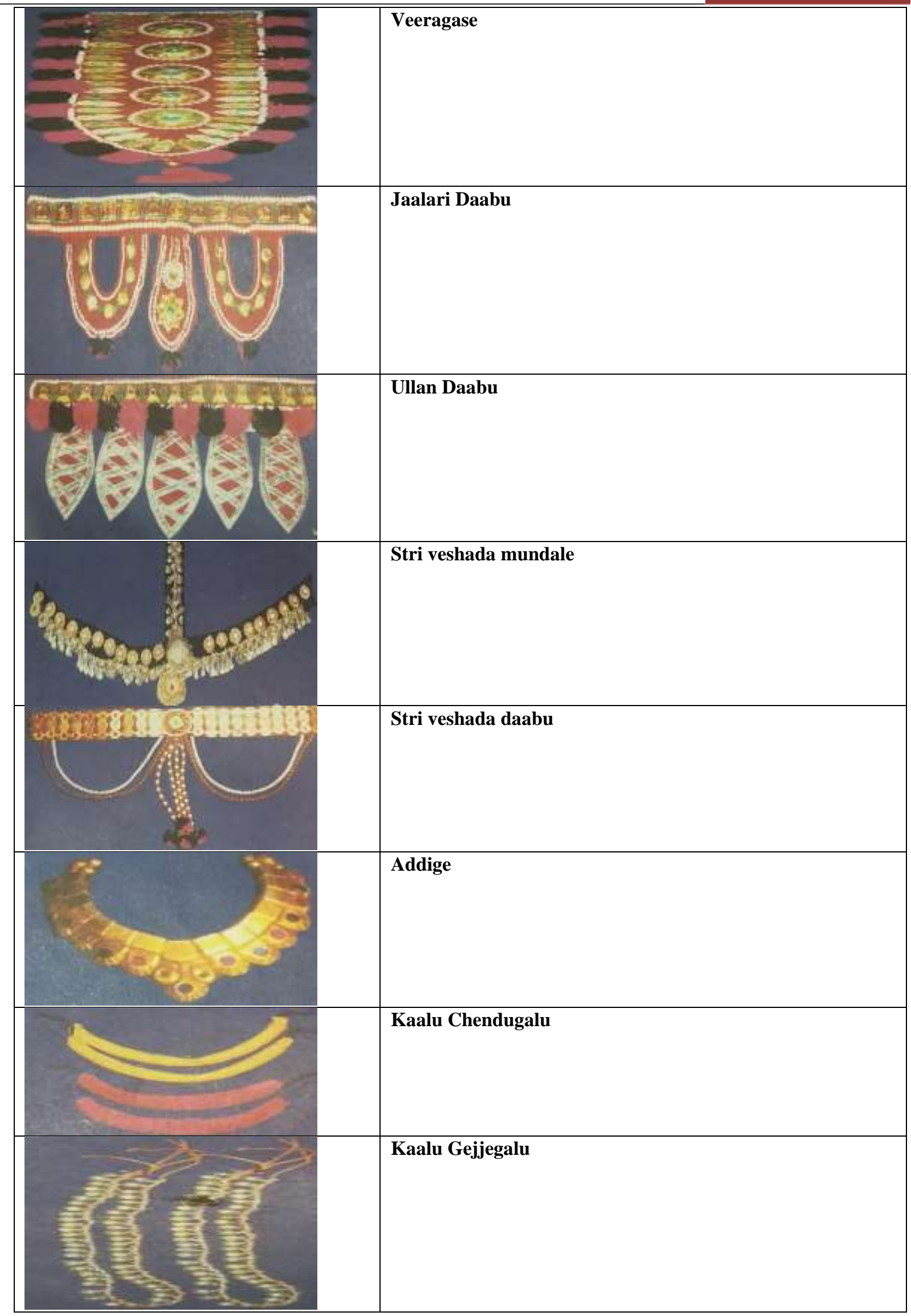


The actor has to do the makeup before dressing. For every character, different types of makeup styles or patterns are used. The Colour used during the facial makeup plays a very important role in identifying the characters on the stage. Make-up styles are predominantly classified based on whether the character is a follower of Lord Vishnu (called Vaishnavas) or lord Shiva (called Shaivas). If the character is a follower of Lord Vishnu then there will be a vertical line pattern with different color patterns on the forehead. If the character is a follower of Lord Shiva, then there will a horizontal line pattern on the forehead. Some types of makeup patterns are listed in the table below. This table lists only some types of makeup patterns because the makeup styles vary from artist to artist depending on his talent in makeup. But every actor has to follow the basic pattern style which includes either horizontal or vertical line patterns.

Table 4: Makeup styles

\begin{tabular}{|l|l|} 
Here some makeup patterns are mentioned. Here \\
we can note that there is a vertical pattern on the \\
forehead in different styles. Some of the \\
characters which follow these kinds of patterns \\
are Devendra, Krishna, Abhimanyu, Sudarshana, \\
Prahlad, Brahma, etc. All these falls under the \\
Vaishnava role category.
\end{tabular}




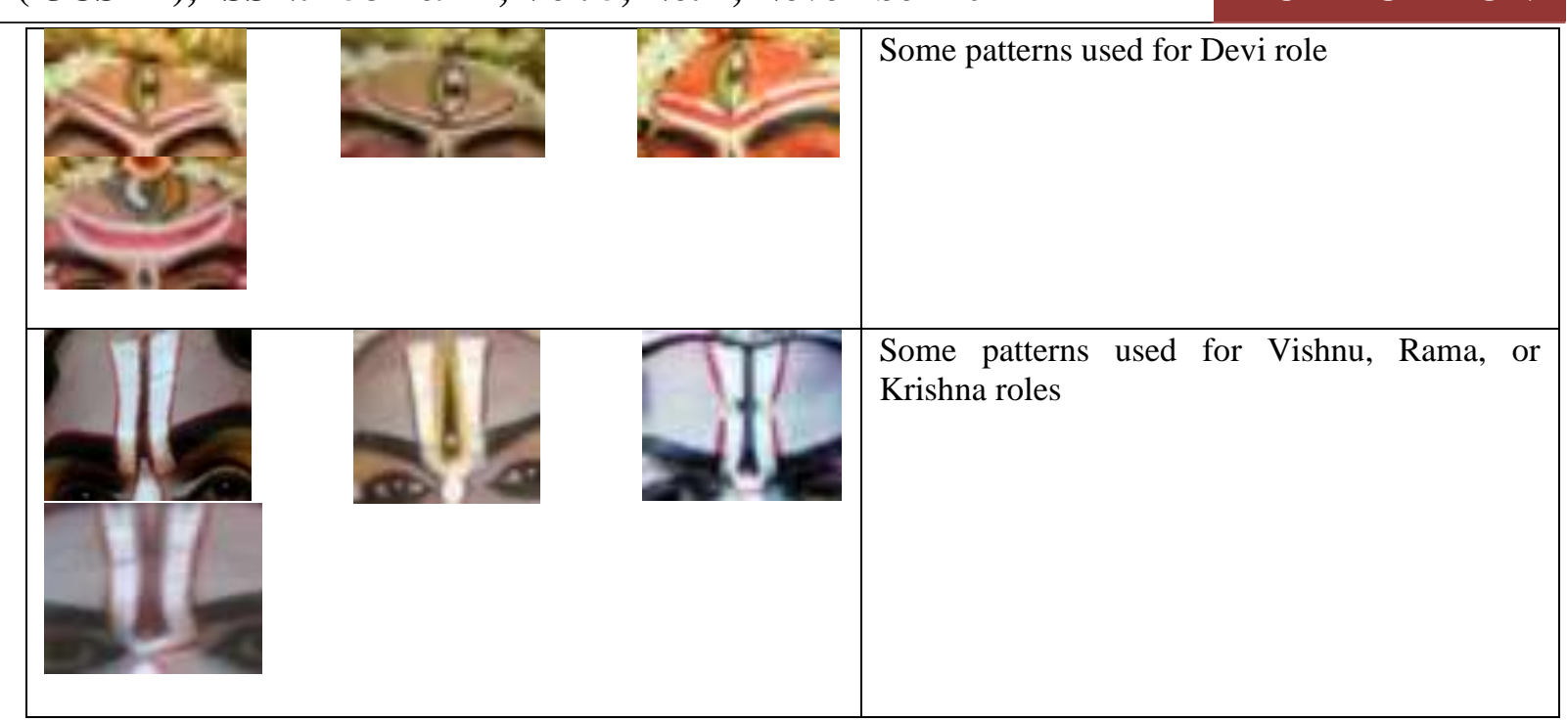

In the above table, only some makeup patterns are mentioned. For every type of role, particular types of patterns must be followed by artists.

At present, the audience will just look into the play and are least bothered about the concepts involved in dressing styles and makeup styles. To understand Yakshagana in-depth, it is necessary to understand the concepts involved behind makeup styles, patterns, and dressing styles. In this survey, we have various types of patterns used in facial makeup, different swords used, distinct crowns, and diverse jewels used during the dressing.

To identify the character on it is very important to note down the facial makeup styles, the way of dressing, and the sword that is being used. Just considering only one parameter is not sufficient to identify a character. For example, the sword Bow and Arrow can be used for almost all types of characters. But there are some swords especially "Shree chakra" which is designed for Lord Vishnu. But in some circumstances, other characters like Goddess Devi may also hold the same sword. So, in these situations, one has to consider more than one parameter to identify a character. To address these complexities, there must exist a model which will make the audience identify the characters easily.

\section{RESEARCH GAPS AND PROPOSAL :}

Currently, there is a very insignificant amount of investigation on the application of technology in the Yakshagana field. More focus has to give to popularizing Yakshagana by making the people understand the concepts involved behind dressing and makeup styles. This survey identifies the following research gaps and suggests the ideal solution.

- Research Gap 1: Complexity in understanding and identifying the different types of crowns in Yakshagana image.

It is very much necessary to understand the different types of crowns used for diverse characters. There is huge scope for research to predict what type of crown is adorned by each character.

- Research Gap 2: Complexity in understanding and identifying the different types of jewels in Yakshagana image.

The Jewels used during the dressing is very specific, varies from character to character. There is a scope for research to predict the types of jewels used by each character.

- Research Gap 3: Difficulty in understanding and identifying the pattern in facial makeup in Yakshagana image is more challenging.

Facial makeup plays a vital role in predicting the character. To date, no research is done on this aspect to predict the character based on the makeup pattern.

- Research Gap 4: Difficulty in predicting the roles played by an artist based on dressing, makeup styles, and sword types.

One or more characters may follow similar patterns in facial makeup. In such cases, it is very difficult to identify the role played by an artist. In these complex situations, more than one parameter must be considered to identify a particular role. There is scope for the research to come up with a system to solve this complex situation. 
- Research Gap 5: To identify the actual person who is playing the role.

Once the actor is dressed up and finished with facial makeup, it is very difficult to identify the artist in person. Research is required if the audience wants to know the artist behind the role.

Different machine learning or image processing algorithms can be used to achieve the above-discussed research gaps. Therefore, there is a huge demand for the best algorithms that provide the ideal solution for the above-stated research gaps. Based on the survey, it is observed that there is not much difference between object detection and face detection. Therefore, the algorithms based on CNN, RCNN, YOLO, Resnet, etc can be applied for detecting objects like crowns, jewels, swords as well as for detecting faces with make-up and without-makeup.

\section{RESEARCH AGENDAS :}

(1) What conceptual model can be used to popularize Yakshagana by giving a technology touch to it?

(2) Which technology platform or algorithms can be used to identify different varieties of crowns, jewels, and swords used in Yakshagana play?

(3) What pattern matching algorithms can be proposed to identify the patterns used in facial makeup?

(4) What technology can be used to identify the character played by an artist based on crown, makeup, and dressing styles?

(5) What methodology can be proposed to encourage society to learn Yakshagana along with the technology?

\section{LIMITATIONS OF THE PROPOSAL :}

Every research has got its own set of limitations. Below is the possible list of limitations that may be considered in the future work.

(1) This proposal is only limited to Yakshagana though our Indian culture is very vast. A similar kind of proposal can be developed for any other cultural area also.

(2) This proposal only concentrates on Mummela though Himmela also plays a significant role in Yakshagana.

(3) This proposal guides people on the appearance of character but it does not educate them with the dance steps they have to perform during the play though it is a part of mummela.

(4) This proposal concentrates on identifying the character based on few parameters like crown-types, makeup-types and cosmetics. Though makeup looks similar for different characters in different plays, identifying the characters may be difficult. One may go for considering more features for classifying the characters.

(5) This proposal identifies the character with simple make-ups. When the makeup is complicated this proposal may give false identification of characters.

\section{SWOC ANALYSIS :}

The goal of a SWOC analysis is to look at strengths, limitations, opportunities, and challenges in a systematic way [98]. Statistics, customer service ratings, and surveys can all be used to document strengths [99]. Weaknesses must be recognized and acknowledged so that they can be addressed quickly before they spread and cause widespread devastation [100]. External opportunities are common. They give businesses the tools they need to succeed [101]. Challenges can be overcome. Threats have the ability to harm a company, but challenges are often present and must be addressed wisely [102]. We conducted a SWOC analysis of the application of technology in the Yakshagana industry to experience its effectiveness.

Table 6: SWOC Analysis

\begin{tabular}{|l|l|}
\hline \multicolumn{1}{|c|}{ Strengths } & \multicolumn{1}{c|}{ Weaknesses } \\
\hline Data availability & Highly fragmented \\
Advancements in technology & Human factor dependency \\
Vast audience reaches & Openness \\
Wide demand from learners & \\
\hline \multicolumn{1}{|c|}{ Opportunities } & \multicolumn{1}{c}{ Challenges } \\
\hline
\end{tabular}


Viewership and Advertisement

Scope for education

Technical Advancements
Data protection, privacy law, and other legal issues

Difficulty in analyzing unstructured data.

Lack of quality content

\section{CONCLUSION :}

Yakshagana is a popular folk theatre form found in the coastal districts. Many of the educational institutions in the coastal region included yashagana as an add-on course in their curriculum. Devotees or fans of yakashagana are also showing more interest in joining and learning Yakshagana through the private coaching centers. But the majority of these training centers or educational institutions teach only himmela and/or dancing steps of Yakshagana. The least importance is given to training people with dressing and makeup styles. Very rarely hands-on workshops were organized and are being conducted to give rough ideas on dressing and makeup styles. Our goal is to educate the people by giving technology touch to Yakshagana. Our research work concentrates on implementing a system using machine learning and image processing to educate the people on dressing and makeup styles which include classifying and identifying varieties of crowns, jewels, \& swords. The proposed model also concentrates on predicting characters based on the facial makeup pattern and predicting the actor in the role. There is a huge scope for research to understand and find out an effective and reliable subset of technologies contributing to the development of Yakshagana.

\section{REFERENCES :}

[1] Padmanabha, K. V., \& Kumar, S. (2020). Folk Media for Agricultural Extension: A Study of Yakshagana-A South Indian Folk Theatre. IJASSH.1(1),1-8.

Google Scholar $\chi^{\top}$

[2] Karanth, K. S. (1958). Yakshagana: a musical dance-drama, 1(1),13-20.

Google Scholar $x^{\top}$

[3] Ashton, M. B. (1969). Yakshagana. A South Indian Folk Theatre. The Drama Review: TDR, 13(3), 148-155.

Google Scholar 7

[4] Upadhyaya, K. S. (1969). Yakshagana Bayalata. Sangeet Natak Akademi, New Delhi, 1(1),1-15. Google Scholar $x^{7}$

[5] Ashton, M. B. (1976). Yakshagana.A Dance Drama of India. Shakti Malik: Abhinav Publications, 1(1), 3-67.

Google Scholar X

[6] Bapat, G. V. (1998). Semiotics of Yakshagana. Udupi: Regional Resource Centre for Folk Performing Arts, 01-25.

[7] Kumar, S. (2010). Role in Yakshagana in Development Communication. Media Researcher, 5(1),5-9.

Google Scholar $x^{7}$

[8] Binder, K. (2012). Re-Use In The Yakshagana Theatre Of Coastal Karnataka. Re-Use-The Art and Politics of Integration and Anxiety, SAGE Publishing India, 1(1), 50-70.

$\underline{\text { Google Scholar } X^{\top}}$

[9] Kumar, S. (2010). Role of Yakshagana in Development Communication. Media Researcher, 5(1),5-9.

Google Scholar $\chi^{7}$

[10] Padmanabha, K. V., \& Kumar, S. (2019). Modern Themes in Yakshagana: Experimentation and Relevance. International Journal of Research and Analytical Reviews, 6(2), 395-401.

Google Scholar $x^{\top}$ 
[11] Padmanabha, K. V., \& Kumar, S. (2020). Health communication through folk media: a study based on Yakshagana - A South Indian dance drama on Covid-19. Mass Communicator: International Journal of Communication Studies, 14(3), 20-26.

Google ScholarX

[12] Chandan, G., Jain, A., \& Jain, H. (2018, July). Real time object detection and tracking using Deep Learning and OpenCV. In 2018 international conference on inventive research in computing applications (ICIRCA), 1(1), 1305-1308.

Google Scholar X

[13] Galvez, R. L., Bandala, A. A., Dadios, E. P., Vicerra, R. R. P., \& Maningo, J. M. Z. (2018, October). Object detection using convolutional neural networks. In TENCON 2018, IEEE Region 10 Conference, 1(1), 2023-2027.

Google Scholar $x^{\top}$

[14] Ren, Y., Zhu, C., \& Xiao, S. (2018). Object detection based on fast/faster RCNN employing fully convolutional architectures. Mathematical Problems in Engineering, 2018, 1-7.

Google ScholarX

[15] Pham, M. T., \& Lefèvre, S. (2018, July). Buried object detection from B-scan ground penetrating radar data using Faster-RCNN. In IGARSS 2018-2018 IEEE International Geoscience and Remote Sensing Symposium, 1(1), 6804-6807.

Google Scholar $\chi^{7}$

[16] Li, Z., Peng, C., Yu, G., Zhang, X., Deng, Y., \& Sun, J. (2018). Detnet: Design backbone for object detection. Proceedings of the European conference on computer vision (ECCV), 1(1), 334-350. Google Scholar X

[17] Womg, A., Shafiee, M. J., Li, F., \& Chwyl, B. (2018, May). Tiny SSD: A tiny single-shot detection deep convolutional neural network for real-time embedded object detection. In 2018 15th Conference on Computer and Robot Vision (CRV), 1(1), 95-101.

Google Scholar X

[18] Sharma, V., \& Mir, R. N. (2019). Saliency guided faster-RCNN (SGFr-RCNN) model for object detection and recognition. Journal of King Saud University-Computer and Information Sciences, 1(1),1-12.

Google Scholar X

[19] Xu, H., Jiang, C., Liang, X., Lin, L., \& Li, Z. (2019). Reasoning-rcnn: Unifying adaptive global reasoning into large-scale object detection. In Proceedings of the IEEE/CVF Conference on Computer Vision and Pattern Recognition, 1(1), 6419-6428.

Google Scholar X

[20] Benjdira, B., Khursheed, T., Koubaa, A., Ammar, A., \& Ouni, K. (2019, February). Car detection using unmanned aerial vehicles: Comparison between faster $\mathrm{r}-\mathrm{cnn}$ and yolov3. International Conference on Unmanned Vehicle Systems-Oman (UVS), 1(1), 1-6.

Google Scholar $\chi^{\top}$

[21] Mao, Q. C., Sun, H. M., Liu, Y. B., \& Jia, R. S. (2019). Mini-YOLOv3: real-time object detector for embedded applications. IEEE Access, 7(1), 133529-133538.

Google Scholar X

[22] Choi, J., Chun, D., Kim, H., \& Lee, H. J. (2019). Gaussian yolov3: An accurate and fast object detector using localization uncertainty for autonomous driving. In Proceedings of the IEEE/CVF International Conference on Computer Vision, 1(1), 502-511.

Google Scholar X

[23] Yi, Z., Yongliang, S., \& Jun, Z. (2019). An improved tiny-yolov3 pedestrian detection algorithm. Optik, 183, 17-23.

Google Scholar $\chi^{7}$ 
[24] Ou, X., Yan, P., Zhang, Y., Tu, B., Zhang, G., Wu, J., \& Li, W. (2019). Moving object detection method via ResNet-18 with encoder-decoder structure in complex scenes. IEEE Access, 7(1), 108152-108160.

Google Scholar $x^{\top}$

[25] Haque, M. F., Lim, H. Y., \& Kang, D. S. (2019, January). Object detection based on vgg with resnet network. International Conference on Electronics, Information, and Communication (ICEIC), 1(1), 1-3.

Google Scholar $\chi^{7}$

[26] Lu, Z., Lu, J., Ge, Q., \& Zhan, T. (2019, July). Multi-object detection method based on YOLO and resNet hybrid networks. In 2019 IEEE 4th International Conference on Advanced Robotics and Mechatronics (ICARM), 1(1), 827-832.

Google Scholar $X^{\top}$

[27] Lu, X., Kang, X., Nishide, S., \& Ren, F. (2019, December). Object detection based on SSD-ResNet. International Conference on Cloud Computing and Intelligence Systems (CCIS), 1(1), 89-92. Google Scholar ${ }^{\top}$

[28] Bai, Z., \& Jiang, D. (2019, November). On the multi-scale real-time object detection using resnet. In Chinese Conference on Pattern Recognition and Computer Vision (PRCV), 1(1), 63-73.

Google Scholar X

[29] Janahiraman, T. V., \& Subuhan, M. S. M. (2019, October). Traffic light detection using TensorFlow object detection framework. In 2019 IEEE 9th International Conference on System Engineering and Technology (ICSET), 1(1), 108-113.

Google Scholar $x^{\top}$

[30] Fang, W., Wang, L., \& Ren, P. (2019). Tinier-YOLO: A real-time object detection method for constrained environments. IEEE Access, 8(1), 1935-1944.

Google Scholar X'

[31] Yundong, L. I., Han, D. O. N. G., Hongguang, L. I., Zhang, X., Zhang, B., \& Zhifeng, X. I. A. O. (2020). Multi-block SSD based on small object detection for UAV railway scene surveillance. Chinese Journal of Aeronautics, 33(6), 1747-1755.

Google Scholar ${ }^{\top}$

[32] Younis, A., Shixin, L., Jn, S., \& Hai, Z. (2020, January). Real-time object detection using pretrained deep learning models MobileNet-SSD. In Proceedings of 2020 the 6th International Conference on Computing and Data Engineering, 1(1), 44-48.

Google Scholar $x^{\top}$

[33] Mahmoud, A., Mohamed, S., El-Khoribi, R., \& Abdelsalam, H. (2020). Object detection using adaptive mask RCNN in optical remote sensing images. Int. J. Intell. Eng. Syst, 13(1), 65-76.

Google Scholar $Z^{\top}$

[34] He, Z., \& Zhang, L. (2020). Domain adaptive object detection via asymmetric tri-way faster-rcnn. In Computer Vision-ECCV 2020: 16th European Conference, Glasgow, UK, August 23-28, 2020, Proceedings, Part XXIV 16, 1(1), 309-324.

Google Scholar X'

[35] Zhao, L., \& Li, S. (2020). Object detection algorithm based on improved YOLOv3. Electronics, 9(3), 537.

Google Scholar $X$

[36] Zhao, H., Zhou, Y., Zhang, L., Peng, Y., Hu, X., Peng, H., \& Cai, X. (2020). Mixed YOLOv3LITE: a lightweight real-time object detection method. Sensors, 20(7), 1861.

Google Scholar X

[37] Zhang, S., Wu, Y., Men, C., \& Li, X. (2020). Tiny YOLO optimization-oriented bus passenger object detection. Chinese Journal of Electronics, 29(1), 132-138.

Google Scholar Х 
[38] Long, X., Deng, K., Wang, G., Zhang, Y., Dang, Q., Gao, Y., ... \& Wen, S. (2020). PP-YOLO: An effective and efficient implementation of object detector. arXiv preprint arXiv:2007.12099, 1(1), $1-8$.

Google Scholar $\not^{7}$

[39] Bochkovskiy, A., Wang, C. Y., \& Liao, H. Y. M. (2020). Yolov4: Optimal speed and accuracy of object detection. arXiv preprint arXiv:2004.10934, 1(1), 1-17.

Google Scholar $\chi^{7}$

[40] Jiang, Z., Zhao, L., Li, S., \& Jia, Y. (2020). Real-time object detection method based on improved YOLOv4-tiny. arXiv preprint arXiv:2011.04244, 1(1), 1-11.

Google Scholar X

[41] Sun, C., Ai, Y., Wang, S., \& Zhang, W. (2021). Mask-guided SSD for small-object detection. Applied Intelligence, 51(6), 3311-3322.

Google Scholar $X^{\top}$

[42] Wang, C. Y., Bochkovskiy, A., \& Liao, H. Y. M. (2021). Scaled-yolov4: Scaling cross stage partial network. IEEE/CVF Conference on Computer Vision and Pattern Recognition, 1(1), 13029-13038. Google Scholar $X^{\top}$

[43] Kose, N., Apvrille, L., \& Dugelay, J. L. (2015, May). Facial makeup detection technique based on texture and shape analysis. In 2015 11th IEEE International Conference and Workshops on Automatic Face and Gesture Recognition (FG), 1(1), 1-7.

Google Scholar $x^{\top}$

[44] Ranjan, R., Patel, V. M., \& Chellappa, R. (2017). Hyperface: A deep multi-task learning framework for face detection, landmark localization, pose estimation, and gender recognition. IEEE transactions on pattern analysis and machine intelligence, 41(1), 121-135.

Google Scholar $X^{\top}$

[45] Sun, X., Wu, P., \& Hoi, S. C. (2018). Face detection using deep learning: An improved faster RCNN approach. Neurocomputing, 1(1), 42-50.

Google Scholar X'

[46] Zhang, C., Xu, X., \& Tu, D. (2018). Face detection using improved faster rcnn. arXiv preprint arXiv:1802.02142, 1(1), 1-9.

Google Scholar X

[47] Masi, I., Wu, Y., Hassner, T., \& Natarajan, P. (2018, October). Deep face recognition: A survey. SIBGRAPI conference on graphics, patterns and images (SIBGRAPI), 1(1), 471-478. Google Scholar X

[48] Bertacchi, M. G., \& Silveira, I. F. (2019, September). Facial Makeup Detection using the CMYK Color Model and Convolutional Neural Networks. XV Workshop de Visão Computacional (WVC), $1(1), 54-60$.

Google Scholar $x^{7}$

[49] Rathgeb, C., Dantcheva, A., \& Busch, C. (2019). Impact and detection of facial beautification in face recognition: An overview. IEEE Access, 1(1), 152667-152678.

Google Scholar $x^{7}$

[50] Ranjan, R., Bansal, A., Zheng, J., Xu, H., Gleason, J., Lu, B., ... \& Chellappa, R. (2019). A fast and accurate system for face detection, identification, and verification. IEEE Transactions on Biometrics, Behavior, and Identity Science, 1(2), 82-96.

Google Scholar ${ }^{\top}$

[51] Joshi, A. S., Joshi, S. S., Kanahasabai, G., Kapil, R., \& Gupta, S. (2020, September). Deep learning framework to detect face masks from video footage. In 2020 12th International Conference on Computational Intelligence and Communication Networks (CICN), 1(1), 435-440.

Google Scholar \ 
[52] Sati, V., Sánchez, S. M., Shoeibi, N., Arora, A., \& Corchado, J. M. (2020, June). Face Detection and Recognition, Face Emotion Recognition Through NVIDIA Jetson Nano. In International Symposium on Ambient Intelligence, 1(1), 177-185.

Google Scholar X

[53] Fang, Z., Ren, J., Marshall, S., Zhao, H., Wang, Z., Huang, K., \& Xiao, B. (2020). Triple loss for hard face detection. Neurocomputing, 398, 1(1), 20-30.

Google Scholar $\chi^{7}$

[54] Zhu, Y., Cai, H., Zhang, S., Wang, C., \& Xiong, Y. (2020). Tinaface: Strong but simple baseline for face detection. arXiv preprint arXiv:2011.13183.,1(1), 1-9.

Google Scholar X'

[55] Ding, X., Raziei, Z., Larson, E. C., Olinick, E. V., Krueger, P., \& Hahsler, M. (2020). Swapped face detection using deep learning and subjective assessment. EURASIP Journal on Information Security, 2020, 1(1), 1-12.

Google Scholar $X^{\top}$

[56] Mandal, B., Okeukwu, A., \& Theis, Y. (2021). Masked Face Recognition using ResNet-50. arXiv preprint arXiv:2104.08997, 1(1),1-8.

Google Scholar $\chi^{7}$

[57] Al-ghanim, F. J., \& mohsin Al-juboori, A. (2021). Detection of Human Faces Covered with disguise and Makeup. Journal of Al-Qadisiyah for computer science and mathematics, 13(3), 68. Google Scholar $\chi^{7}$

[58] Rathgeb, C., Drozdowski, P., \& Busch, C. (2021, January). Detection of makeup presentation attacks based on deep face representations. International Conference on Pattern Recognition (ICPR), l(1), 3443-3450.

Google Scholar $X^{\top}$

[59] Lobo, V. S., \& Bhat, K. S. (2021). An Analysis of Indian Entertainment Industry-Past, Present, and Future. International Journal of Management, Technology and Social Sciences (IJMTS), 6(2), 88-99.

Google Scholar $\chi^{7}$

[60] Naik, A. D., \& Supriya, M. (2021). Classification of Indian Classical Dance 3D Point Cloud Data Using Geometric Deep Learning. Computational Vision and Bio-Inspired Computing, 1(1), 81-93. Google Scholar $X^{\top}$

[61] Somayaji, S., Srivatsa, S. R., \& Pranav, D. M. (2021). Application of materials-engineering research to Indian traditional artforms, A case-study: Bhujakeerthi of Yakshagana. Materials Today: Proceedings. 46(7), 2379-2386.

Google Scholar $\chi^{\top}$

[62] Hu, H., Gu, J., Zhang, Z., Dai, J., \& Wei, Y. (2018). Relation networks for object detection. In Proceedings of the IEEE conference on computer vision and pattern recognition, 1(1), 35883597.

Google Scholar $\chi^{7}$

[63] Zou, Z., Shi, Z., Guo, Y., \& Ye, J. (2019). Object detection in 20 years: A survey. arXiv preprint arXiv:1905.05055, 1(1), 1-39.

Google Scholar ${ }^{7}$

[64] Zhao, Z. Q., Zheng, P., Xu, S. T., \& Wu, X. (2019). Object detection with deep learning: A review. IEEE transactions on neural networks and learning systems, 30(11), 3212-3232.

Google Scholar $\chi^{7}$

[65] Ghiasi, G., Lin, T. Y., \& Le, Q. V. (2019). Nas-fpn: Learning scalable feature pyramid architecture for object detection. In Proceedings of the IEEE/CVF Conference on Computer Vision and Pattern Recognition, 1(1), 7036-7045.

Google Scholar X 
[66] Zhao, J. X., Liu, J. J., Fan, D. P., Cao, Y., Yang, J., \& Cheng, M. M. (2019). EGNet: Edge guidance network for salient object detection. In Proceedings of the IEEE/CVF International Conference on Computer Vision, 1(1),8779-8788.

Google Scholar X

[67] Tian, Z., Shen, C., Chen, H., \& He, T. (2019). Fcos: Fully convolutional one-stage object detection. In Proceedings of the IEEE/CVF international conference on computer vision, 1(1), 9627-9636. Google Scholar $X^{7}$

[68] Zhou, X., Zhuo, J., \& Krahenbuhl, P. (2019). Bottom-up object detection by grouping extreme and center points. In Proceedings of the IEEE/CVF Conference on Computer Vision and Pattern Recognition, 1(1), 850-859.

Google Scholar 7

[69] Qin, X., Zhang, Z., Huang, C., Gao, C., Dehghan, M., \& Jagersand, M. (2019). Basnet: Boundaryaware salient object detection. In Proceedings of the IEEE/CVF Conference on Computer Vision and Pattern Recognition, 1(1), 7479-7489.

Google Scholar X

[70] Shao, S., Li, Z., Zhang, T., Peng, C., Yu, G., Zhang, X., ... \& Sun, J. (2019). Objects365: A largescale, high-quality dataset for object detection. In Proceedings of the IEEE/CVF International Conference on Computer Vision, 1(1), 8430-8439.

Google Scholar X

[71] Brazil, G., \& Liu, X. (2019). M3d-rpn: Monocular 3d region proposal network for object detection. In Proceedings of the IEEE/CVF International Conference on Computer Vision, 1(1), 9287-9296. Google Scholar $x^{\nearrow}$

[72] Pang, J., Chen, K., Shi, J., Feng, H., Ouyang, W., \& Lin, D. (2019). Libra r-cnn: Towards balanced learning for object detection. In Proceedings of the IEEE/CVF Conference on Computer Vision and Pattern Recognition, 1(1), 821-830.

Google Scholar $x^{7}$

[73] Tan, M., Pang, R., \& Le, Q. V. (2020). Efficientdet: Scalable and efficient object detection. In Proceedings of the IEEE/CVF conference on computer vision and pattern recognition, 1(1), 10781-10790.

Google Scholar $x^{7}$

[74] Kim, K. H., Hong, S., Roh, B., Cheon, Y., \& Park, M. (2016). Pvanet: Deep but lightweight neural networks for real-time object detection. arXiv preprint arXiv:1608.08021, 1(1), 1-7.

Google Scholar $\chi^{\top}$

[75] Redmon, J., Divvala, S., Girshick, R., \& Farhadi, A. (2016). You only look once: Unified, realtime object detection. In Proceedings of the IEEE conference on computer vision and pattern recognition, 1(1),779-788.

Google Scholar X

[76] Mao, H., Yao, S., Tang, T., Li, B., Yao, J., \& Wang, Y. (2016). Towards real-time object detection on embedded systems. IEEE Transactions on Emerging Topics in Computing, 6(3), 417-431. Google Scholar $x^{\top}$

[77] Huang, R., Pedoeem, J., \& Chen, C. (2018, December). YOLO-LITE: a real-time object detection algorithm optimized for non-GPU computers. IEEE International Conference on Big Data (Big Data), 1(1), 2503-2510.

Google Scholar $X^{7}$

[78] Ophoff, T., Van Beeck, K., \& Goedemé, T. (2019). Exploring RGB+ Depth fusion for real-time object detection. Sensors, 19(4), 866.

Google Scholar X

[79] Lu, S., Wang, B., Wang, H., Chen, L., Linjian, M., \& Zhang, X. (2019). A real-time object detection algorithm for video. Computers \& Electrical Engineering, 77(1), 398-408. 
Google Scholar $X^{\top}$

[80] Liu, L., Li, H., \& Gruteser, M. (2019). Edge assisted real-time object detection for mobile augmented reality. In The 25th Annual International Conference on Mobile Computing and Networking, 1(1),1-16.

Google Scholar $\not 7$

[81] Liu, Z., Zheng, T., Xu, G., Yang, Z., Liu, H., \& Cai, D. (2020). Training-time-friendly network for real-time object detection. In Proceedings of the AAAI Conference on Artificial Intelligence, 34(7), 11685-11692.

Google Scholar X

[82] Jiang, Z., Zhao, L., Li, S., \& Jia, Y. (2020). Real-time object detection method based on improved YOLOv4-tiny. arXiv preprint arXiv:2011.04244.1(1), 1-11.

Google Scholar X

[83] Masi, I., Wu, Y., Hassner, T., \& Natarajan, P. (2018). Deep face recognition: A survey. In 2018 31st SIBGRAPI conference on graphics, patterns and images, 1(1), 471-478.

Google Scholar X

[84] Wang, F., Chen, L., Li, C., Huang, S., Chen, Y., Qian, C., \& Loy, C. C. (2018). The devil of face recognition is in the noise. In Proceedings of the European Conference on Computer Vision, 1(1), 765-780.

Google Scholar X

[85] Deng, J., Guo, J., Xue, N., \& Zafeiriou, S. (2019). Arcface: Additive angular margin loss for deep face recognition. In Proceedings of the IEEE/CVF Conference on Computer Vision and Pattern Recognition, 1(1), 4690-4699.

Google Scholar ${ }^{7}$

[86] Guo, G., \& Zhang, N. (2019). A survey on deep learning-based face recognition. Computer vision and image understanding, 189, 102805.

Google Scholar $x^{7}$

[87] Deng, J., Guo, J., Zhang, D., Deng, Y., Lu, X., \& Shi, S. (2019). Lightweight face recognition challenge. In Proceedings of the IEEE/CVF International Conference on Computer Vision Workshops, 1(1), 1-9.

Google Scholar $x^{\nearrow}$

[88] Adjabi, I., Ouahabi, A., Benzaoui, A., \& Taleb-Ahmed, A. (2020). Past, present, and future of face recognition: A review. Electronics, 9(8), 1188.

Google Scholar X

[89] Chang, J., Lan, Z., Cheng, C., \& Wei, Y. (2020). Data uncertainty learning in face recognition. In Proceedings of the IEEE/CVF Conference on Computer Vision and Pattern Recognition, 1(1), 5710-5719.

Google Scholar 77

[90] Wang, M., \& Deng, W. (2021). Deep face recognition: A survey. Neurocomputing, 429, 215-244. Google Scholar X

[91] Deng, J., Guo, J., An, X., Zhu, Z., \& Zafeiriou, S. (2021). Masked face recognition challenge: The insight face track report. In Proceedings of the IEEE/CVF International Conference on Computer Vision, 1(1), 1437-1444.

Google Scholar X

[92] Chen, C., Dantcheva, A., \& Ross, A. (2013, June). Automatic facial makeup detection with application in face recognition. In 2013 international conference on biometrics 1(1), 1-8.

Google Scholar $x^{\top}$ 
[93] Kotwal, K., Mostaani, Z., \& Marcel, S. (2019). Detection of age-induced makeup attacks on face recognition systems using multi-layer deep features. IEEE Transactions on Biometrics, Behavior, and Identity Science, 2(1), 15-25.

Google Scholar X

[94] Saeed, U., Masood, K., \& Dawood, H. (2021). Illumination normalization techniques for makeupinvariant face recognition. Computers \& Electrical Engineering, 89, 106921.

Google Scholar $\not^{\top}$

[95] Alzahrani, T., Al-Bander, B., \& Al-Nuaimy, W. (2021). Deep Learning Models for Automatic Makeup Detection. AI, 2(4), 497-511.

Google Scholar X'

[96] Gulati, K., Verma, G., Mohania, M., \& Kundu, A. (2021). BeautifAI--A Personalised Occasionoriented Makeup Recommendation System. arXiv preprint arXiv:2109.06072, 1(1), 1-8.

Google Scholar $x^{7}$

[97] Ibsen, M., González-Soler, L. J., Rathgeb, C., Drozdowski, P., Gomez-Barrero, M., \& Busch, C. (2021). Differential Anomaly Detection for Facial Images. arXiv preprint arXiv:2110.03464, 1(1), $1-6$.

Google Scholar X

[98] Aithal, P. S., \& Kumar, P. M. (2015). Applying SWOC analysis to an institution of higher education. International Journal of Management, IT and Engineering, 5(7), 231-247.

Google Scholar X

[99] Anantha Murthy, \& Nethravathi P. S. (2021). The Evolution of the E-Vehicle Industry and its Path Towards Setting up Dominance in Automobile Industry - A Case Study. International Journal of Case Studies in Business, IT and Education (IJCSBE), 5(2), 38-49.

Google Scholar X

[100] Anantha Murthy, \& Nethravathi P. S. (2021). The Future with New Brand Identity - Success Story of Capgemini: A Case Study. International Journal of Case Studies in Business, IT and Education (IJCSBE), 5(1), 244-255.

Google Scholar $X^{\top}$

[101] Laveena C. Crasta, \& Shailashri V. T. (2021). A Comprehensive Study of Talent Management Process adopted by Tata Consultancy Services (TCS). International Journal of Case Studies in Business, IT and Education (IJCSBE), 5(1), 267-281.

Google Scholar X'

[102] Yogish Pai U, \& Nandha Kumar K.G. (2021). E-Commerce to Multinational Conglomerate: Journey of Alibaba Group - A Case Study. International Journal of Case Studies in Business, IT and Education (IJCSBE), 5(1), 25-35.

Google Scholar X

************* 